\title{
Photoelastic analysis of all-on-four concept using different implants angulations for maxilla
}

\author{
Castelo Pedro Vemba CIDADE(a) \\ Marcele Jardim PIMENTEL(b) \\ Regiane Cristina do AMARAL ${ }^{(c)}$ \\ Mauro Antonio de Arruda \\ NÓBILO(b) \\ José Ricardo de Albergaria \\ BARBOSA $^{(a)}$ \\ (a) Department of Surgery, Piracicaba \\ Dental School, University of Campinas \\ - UNICAMP, Piracicaba, SP, Brazil. \\ (b)Department of Prosthodontics and \\ Periodontology, Piracicaba Dental School, \\ University of Campinas - UNICAMP, \\ Piracicaba, SP, Brazil. \\ (c)Department of Community Dentistry, \\ Piracicaba Dental School, University of \\ Campinas - UNICAMP, Piracicaba, SP, Brazil.
}

Declaration of Interests: The authors certify that they have no commercial or associative interest that represents a conflict of interest in connection with the manuscript.

Corresponding Author:

José Ricardo Albergaria Barbosa

Email:monokuame@yahoo.com.br

DOI: 10.1590/1807-3107BOR-2014.vol28.0051

Submitted: Mar 21, 2014

Accepted for publication: Jun 24, 2014

Last revision: Aug 21, 2014
Abstract: Conventional tilted implants are used in oral rehabilitation for heavily absorbed maxilla to avoid bone grafts; however, few research studies evaluate the biomechanical behavior when different angulations of the implants are used. The aim of this study was evaluate, trough photoelastic method, two different angulations and length of the cantilever in fixed implant-supported maxillary complete dentures. Two groups were evaluated: G15 (distal tilted implants $15^{\circ}$ ) and G35 (distal tilted implants $\left.35^{\circ}\right) \mathrm{n}=6$. For each model, 2 distal tilted implants $(3.5 \times 15 \mathrm{~mm}$ long cylindrical cone) and 2 parallel tilted implants in the anterior region $(3.5 \times 10 \mathrm{~mm})$ were installed. Photoelastic models were submitted to three vertical load tests: in the end of cantilever, in the last pillar and in the all pillars at the same time. We obtained the shear stress by Fringes software and found values for total, cervical and apical stress. The quantitative analysis was performed using the Student tests and Mann-Whitney test; $p \geq 0.05$. There is no difference between G15 and G35 for total stress regardless of load type. Analyzing the apical region, G35 reduced strain values considering the distal loads (in the cantilever $p=0.03$ and in the last pillar $p=0.02$ ), without increasing the stress level in the cervical region. Considering the load in all pillars, G35 showed higher stress concentration in the cervical region $(p=0.04)$. For distal loads, G15 showed increase of tension in the apical region, while for load in all pillars, G35 inclination increases stress values in the cervical region.

Keywords: Dental Implants; Maxilla; Bone Resorption.

\section{Introduction}

The oral rehabilitation of atrophic edentulous maxilla with dental implants is limited by anatomic conditions. The anterior region has a sufficient alveolar crest while in the posterior area a severe bone resorption is present. ${ }^{1}$ This limitation is due to the reduced quantity and quality of bone available, as well as by the presence of pneumatized maxillary sinuses. In these cases, previous surgical maneuvers, such as interposition graft, obtained from a extra oral donor sites, in Le Fort I osteotomy, techniques of onlay bone graft or sinus lift procedures in the posterior maxilla, are necessary for obtaining bone structure that enables the placement of implants. ${ }^{2,3,4,5}$ These techniques have limitations ranging from the need for multiple surgical procedures, greater morbidity, postopera- 
tive long interval for consolidation of the bone graft for continued rehabilitation. ${ }^{6}$ These factors decrease the acceptability of patients.

Some alternatives are used as zygomatic implants, short implants and/or angled ones, used to eliminate or reduce the need for graft procedures. Zygomatic implants require extensive surgical technique, training, detailed anatomical knowledge and skill, though the installation of angled implants does not require specific training beyond the traditional methods of implant placement. ${ }^{7}$ In addition it can result in prosthetic complications with difficult resolution.

The all-on-four concept consists of rehabilitation with fixed dentures supported by four implants, being two in the anterior region (vertical position) and two tilted in the posterior region. This technique was introduced in 2003 for mandible, and in 2005 for maxillary rehabilitations. The inclination was idealized to avoid anatomic obstacles, and to reduce the extension of cantilever. ${ }^{8}$ This allows cases with severe resorption to be rehabilitated with reduce bone grafting procedures and enables immediate prosthetic rehabilitation of patients seeking a minimum surgical time with a reduced number of implants without losing the expectation of success in the treatment. ${ }^{9}$ Tilted implants also allow an increase of length of implants and reduced cantilever extension ${ }^{10,11}$ without difference in marginal bone loss and implant survival. ${ }^{12}$

The term tilted implants refers to implants placed at $15^{\circ}$ or larger angles than the traditional vertical implants. This technique offers a rehabilitation treatment with less morbidity and lower costs. Despite the advantages, the inclination of implants can change the stress behaviour at bone-implant interface. ${ }^{13,14,15}$ The benefits and limitations of treatment with vertical versus inclined mandibular implants, as well as planning with or without subsequent cantilever prosthesis have been widely discussed. However, biomechanical advantages associated with cantilevers in fixed prosthodontics and tilted implants in the maxilla are less well documented in the literature. Furthermore there is little knowledge about the more advantageous implant inclination angle. Thus, the aim of this study was to evaluate the stress distribu- tion in distal tilted implants in all-on-four arrangements with different angle of inclination $\left(15^{\circ}\right.$ and $35^{\circ}$ ) in maxillary rehabilitations.

\section{Methodology}

For this study, we manufactured a skull of polyurethane similar to a human by prototyping were the implants are installed (National Bone ${ }^{\circledR}$ Ltda., Jaú, Brazil). The implant arrangement was transferred to the models in photoelastic resin (1,500 kg GIV Polipox Flexible Silicone Rubber and ASB - 10 Blue - POLIPOX ${ }^{\circledR}$ Ltda., São Paulo,

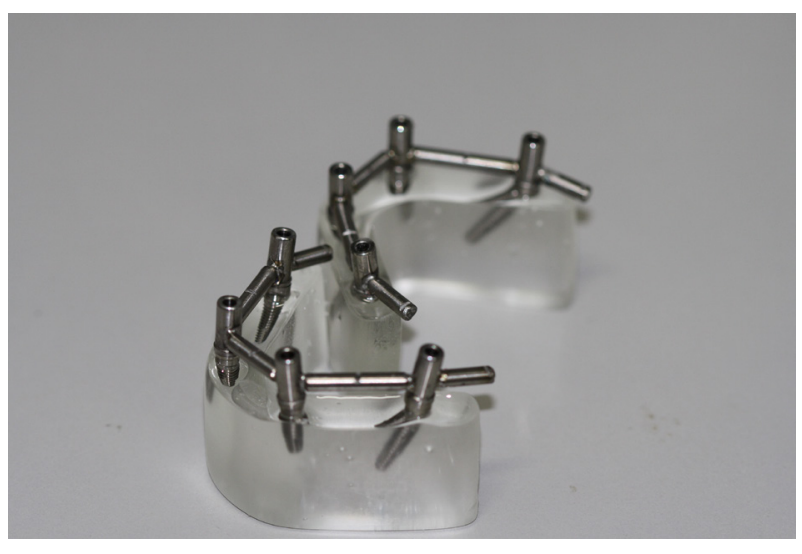

Figure.1: Photoelastic model (GIV Flexible Silicone Rubber and ASB - 10 Blue - POLIPOX ${ }^{\circledR}$ ).

Brazil) plan, and without complex anatomy to permit stress analyses (Figure 1).

For this study, we used conventional implants from INP System (National Prosthetics Implant System - Porous treated, high-power cutting; micro coils Conus ${ }^{\circledast}$, São Paulo, Brazil), cylindrical and conical in the apex, with external hexagon and $3.5 \mathrm{~mm}$ of diameter and $10 \mathrm{~mm}$ of length used to anterior region, and 15 $\mathrm{mm}$ of length used to posterior region of the maxilla.

The samples were divided into two groups:

G15: 3 models with two conventional implants installed parallel in the anterior region $(3.5 \times 10 \mathrm{~mm})$ connected by a laser welding titanium bar to two distal implants $(3.5 \times 15 \mathrm{~mm})$ tilted with $15^{\circ}$, and 10 $\mathrm{mm}$ bilateral cantilevers.

G35: 3 models with two conventional implants installed parallel in the region anterior $(3.5 \times 10 \mathrm{~mm})$ 
connected by a laser welding titanium bar to two distal implants $(3.5 \times 15 \mathrm{~mm})$ tilted with $35^{\circ}$, and $8 \mathrm{~mm}$ bilateral cantilevers.

\section{Photoelastic analysis}

The photoelastic method can be applied from the simplification of complex models, ${ }^{16,17}$ where the formation of colors fringes allows the visualization of the stress behaviour. ${ }^{18,19,20}$ The models were analyzed from two sides (left and right). Qualitative analysis of the stress distribution was made using images obtained from circular polariscope. This unit was attached to a digital camera, which allowed the record of isochromatic fringes produced at the time of loading. For application of the load, was did a V-shaped cut on a threaded bar which was screwed into the load cell. The load was applied gradually until the load of $0.50 \mathrm{kgf}$. This load was calculated in a previous pilot study based on the order formation of fringes to permit quantitative analysis on the software. To this, was made a model index with known dimensions ( $25 \mathrm{~mm}$ length, $22 \mathrm{~mm}$ high, and $10 \mathrm{~mm}$ thick), and 15 points were determined around the implant for the analysis of maximum shear stress $(\mathrm{T})$ in the program Fringes ${ }^{\circledR}\left(\right.$ MATLAB $^{\circledR}$ environment, UFU Uberlândia, Brazil) (Figure 2).

Both sides of the models were analyzed and the plan face was positioned parallel to the polaroscope filters and camera lens (Canon EOS Rebel XS Digital

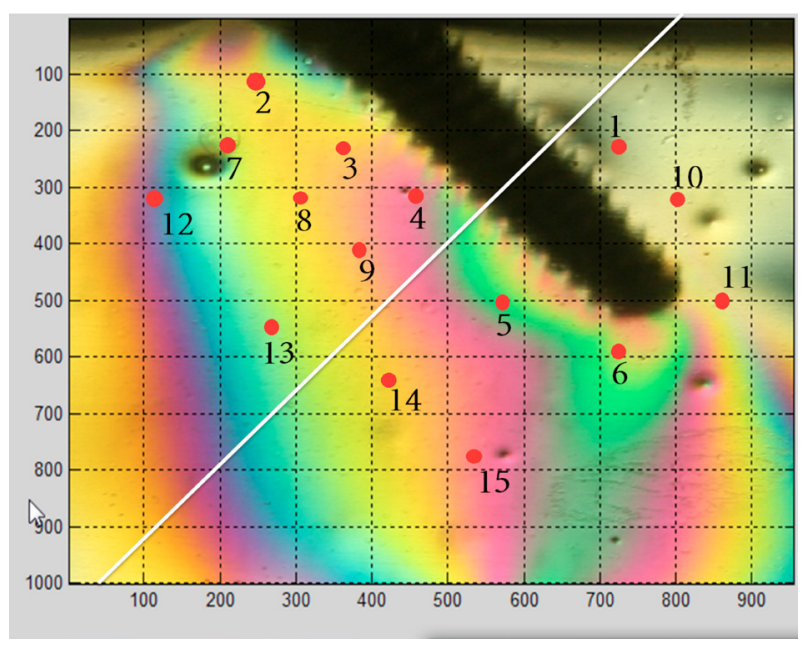

Figure. 2: Pre-determinate points around the implant in the apical and cervical region.
SLR with telephoto lens Canon EF 100mm/2.8 USM - Canon ${ }^{\circledast}$, Tokio, Japan). The machine was positioned on a tripod for the standardization of the photos. The load was applied three times in different conditions: A) in the end of cantilever, B) in the last pillar, C) in all pillars at the same time, with the help of a resin platform to exclude the cantilever influence (Figure 3). The presence of the fringes was observed after the impact of the loads and recorded for all samples. The fractional fringe order for the calculation of maximum shear stress was obtained by the program Fringes ${ }^{\circledR}$.

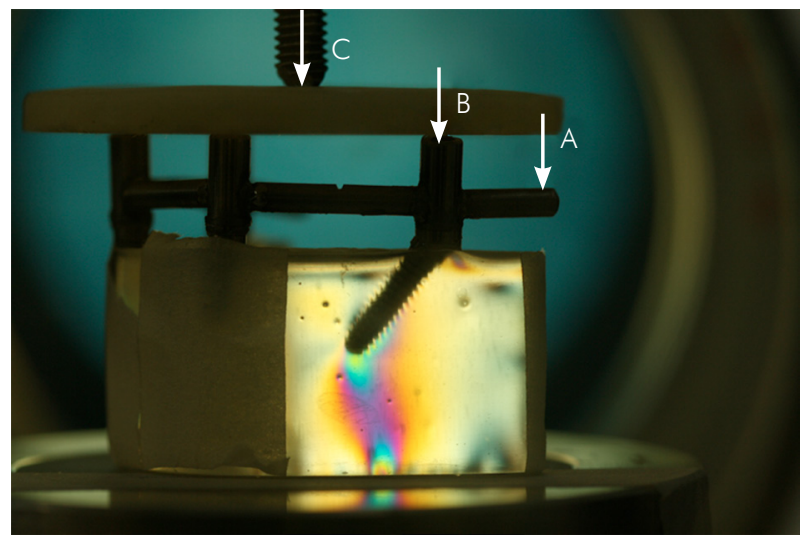

Figure. 3: Different load application to the both groups. A) the end of cantilever, B) the last pillar, C) all pillars at the same time.

The fringes are observed by isochromatic form where $\mathrm{N}=0$ (black), $\mathrm{N}=1$ (red blue - low intensity), $\mathrm{N}=2$ (red green - medium intensity), $\mathrm{N}=3$ (pink - high intensity). ${ }^{21}$ The results were tabulated and divided into: total stress experienced by the implant represented by all points, the cervical area, and the apical (Figure 2), for both groups. For statistical analysis of quantitative data, was used the SAS (Statistical Analysis System 9.1, Institute Inc., Cary, USA) twoway analysis ANOVA, with a significance level of $5 \%$.

\section{Results}

There was no statistically significant difference between implant angles of $15^{\circ}$ and $35^{\circ}$ considering a medium of total stress for all kinds of load. When analyzing the stress distribution in the apical region, there is a statistically significant difference between implants angle when considering a 
distal load (cantilever and the last pillar). In these situations of load, the G35 reduced the strain values. However, when the load was distributed in all pillars at the same time, there was no difference between the groups. For stress in the cervical region regarding loads in the cantilever extension or at the last pillar, there was no statistically significant difference between G15 and G35; however, there is a statistically significant difference considering the load distributed in all pillars at the same time. In this condition, the angle of $15^{\circ}$ showed lower values of strain (Table 1).

Graph 1 represents the behavior of the two groups under load in the cantilever extension. This showed that the G15 concentrated more strain around the implant especially in the apical region (points 5, 6, 11, 14 and 15). In Graph 2, represent the behavior of the both groups under load in the last pillar. The peak value is also for the G15 in the apical region (point 11). However, when the load was distributed to all pillars, the behavior changed and the G35 showed the highest values, especially in the cervical points $(2,3,4,7,8,9,12$ and 13) (Graph 3).

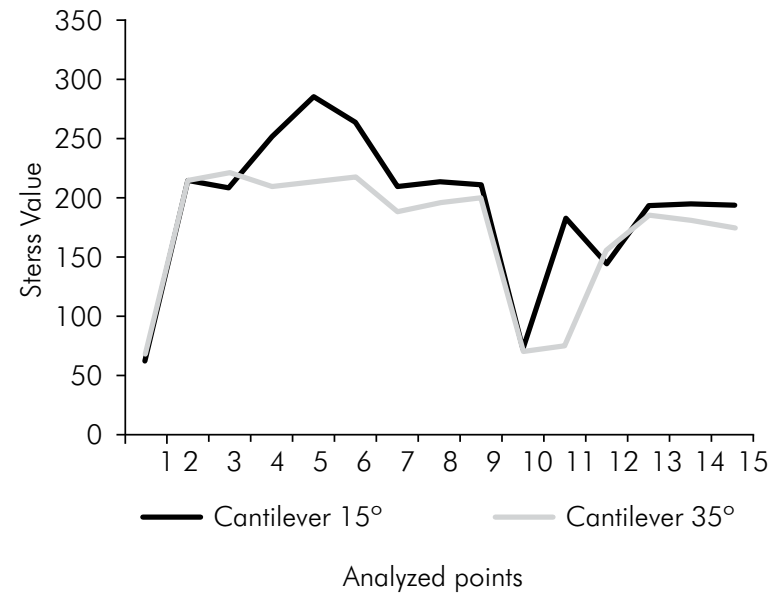

Graph 1. Stress behavior for points analyzed per group for load at the end of cantilever.

The photoelasticity technique allows the analysis of stress throughout the photoelastic model, providing the location of the concentrations of stress, being also indicated for complex systems. ${ }^{16,17}$ This method has been widely applied in dentistry by allowing direct observation of the stress distribution in structures due to the ability of some colorless materials

Table 1. Shear stress mean to the two groups in three loads simulation.

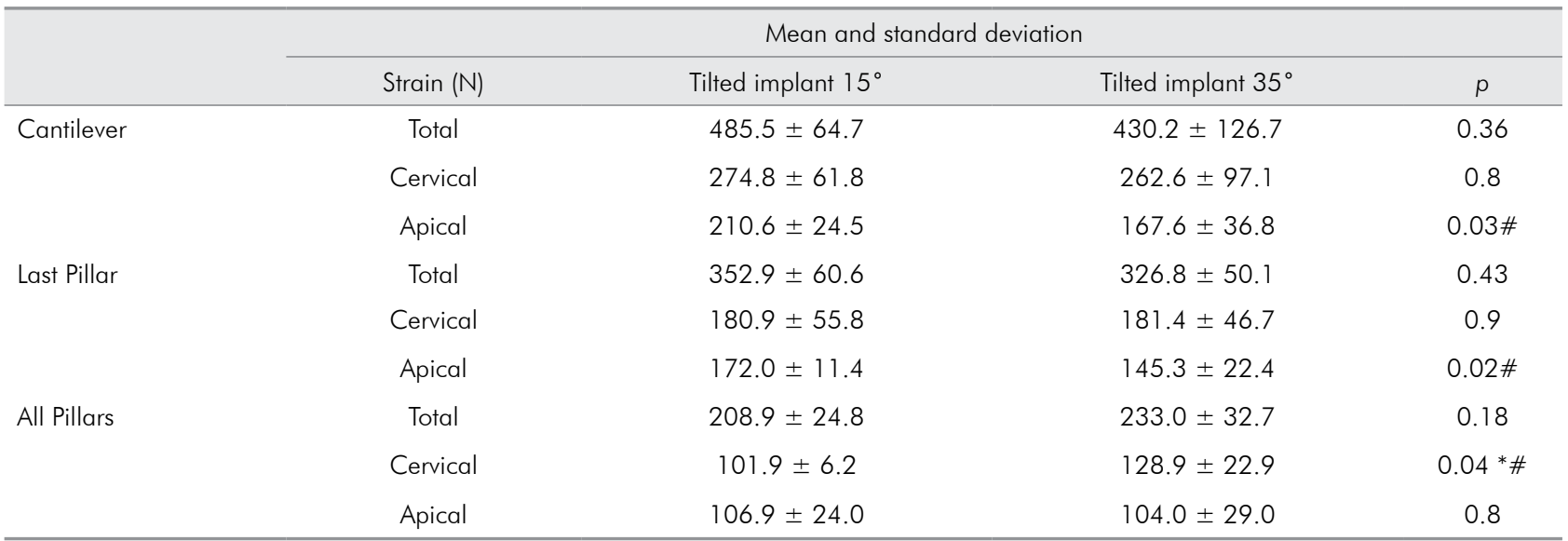

* Mann Whitney test.

\section{Discussion}

In this study was evaluated the stress distribution around the tilted distal implant in all-on-four configurations, after three axial loads in a photoelastic model mimicking an edentulous atrophic maxilla. to generate color patterns known as isochromatic fringes during loading and observed in polarized light. ${ }^{18,19,20,21}$ One limitation of this technique is the reproducibility of the physical characteristics of the peri-implant tissues, since the photoelastic model has 


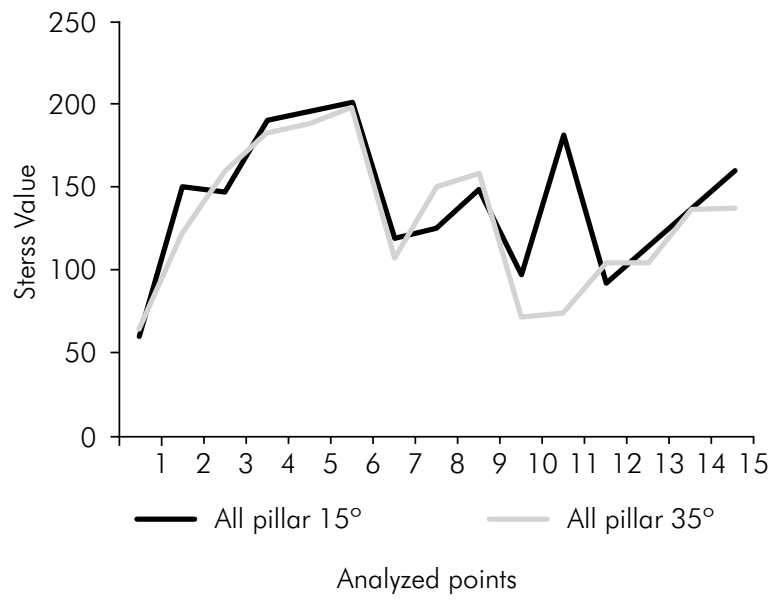

Graph 2. Stress behavior for points analyzed per group for load in the last pillar.

homogeneous and isotropic properties, while bone has variations in the modulus of elasticity according to the region. . $2,23,24,25$ However, this method is used to evaluate behavior and stress tendency on the rehabilitations of implants.

Tilted implants are a maneuver to avoid anatomic limitations ${ }^{1}$ and allow the use of implants with longer length, besides reducing the extension of the cantilever. ${ }^{10,11}$ Despite this, a biomechanical study has concluded that the tilting of the implants induced a high stress level in bone-implant interface compared to parallel model. ${ }^{13,14,15}$ A 3D finite element analysis demonstrated that the increase of tension on the implants was proportional to the lengths of cantilever, which favors the use of tilted implants since they reduce the size thereof. ${ }^{11}$ However few studies compare different degree of inclinations or different load conditions. Considering the distal load was found that the increase of the implant inclination from $15^{\circ}$ to $35^{\circ}$ did not resulted in high stress values, without cervical or apical stress concentration. The length reduction of cantilever associated with the fixed prosthetic design involving angulated implants probably plays a key role in reducing periimplant tension around the implants. ${ }^{26}$ The higher the slope of the implant the smaller the cantilever, thus allowing greater distribution of forces and rehabilitation with more dental elements, favoring masticatory quality. ${ }^{27}$ Under cantilever load the G35 had lower stress values while the G15 concentrated

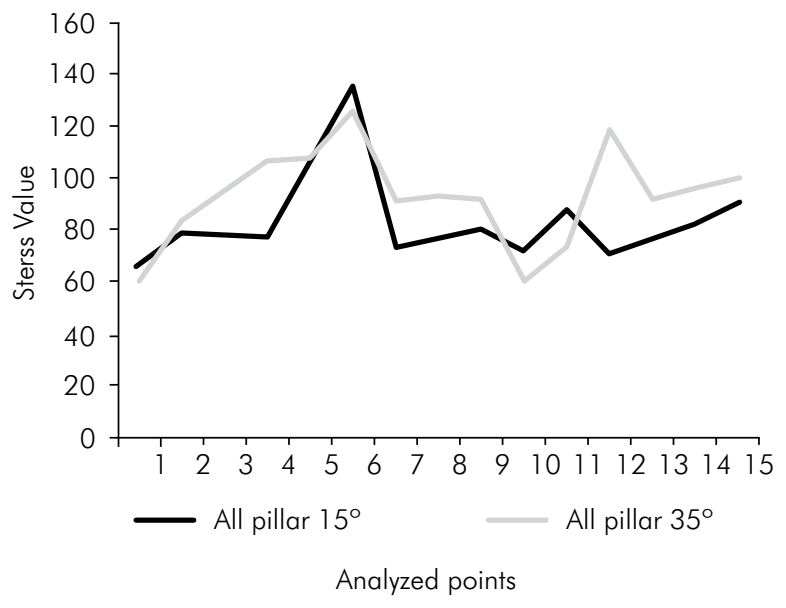

Graph 3. Stress behavior for points analyzed per group for load in all pillars simultaneously.

the stress in the apical region. The implant inclination reflect directly in the cantilever extension and this can be influenced the reduction of stress values to G35 on distal loads. This is an advantage for high implant inclination. The load in the cantilever showed the highest values of strain for all analyses, this was expected since that the increase in the cantilever extension was proportional to the increase of tension. ${ }^{11}$

When submitted to this load model the lower inclination of the implant $\left(15^{\circ}\right)$ resulted in increase of the stress values in the apical region. Comparing the stresses in the apical region was observed that there are significant statistical differences between the angles, with the biggest stresses for the implant with the angulation of $15^{\circ}$, which seems to be not harmful. The oral access to implant insertion is easier with lower inclination and represents an advantage.

Nevertheless when the load was distributed by all pillars the G35 showed high values of stress especially in the cervical region. When this load was applied was not consider the cantilever extension because is concentrated in the abutments, and isolates this variable. The stress concentration in cervical region can be favorable to marginal bone loss. However, a 1-year retrospective clinical study found no difference in the loss of marginal bone and a survival rate of $97.9 \%$ for tilted implants in the maxilla. ${ }^{12}$

A limiting factor is the inability to assess the prosthetic components in this experiment study allows us 
not knowing if there is any reflection of these components in this behavior, limiting the discussion. Was suggests that a lower inclination in distal implants allows a reduction in cantilever length, compared with parallel models, and leads the stress to the apical region regardless of the type of loading. Beside this, the lower inclination is more clinically viable for surgical insertion.

\section{References}

1. Krekmanov L, Kahn M, Rangert B, Lindström H. Tilting of posterior mandibular and maxillary implants for improved prosthesis support. Int J Oral Maxillofac Implants. 2000 MayJun;15(3):405-14.

2. Astrand P, Nord PG, Brånemark PI. Titanium implants and onlay bone graft to the atrophic edentolous maxilla: a 3-year longitudinal study. Int J Oral Maxillofac Surg. 1996 Feb;25(1):25-9

3. Wannfors K, Johansson B, Hallman M, Strandkvist T. A prospective randomized study of 1- and 2-stage sinus inlay bone grafts: 1-year follow-up. Int J Oral Maxillofac Implants. 2000 Sep-Oct;15(5):625-32.

4. Wiltfang J, Schulte-Mosgau S, Nkenke E, Thorwarth M, Neukam FW, Schlegel KA. Onlay augmentation versus sinuslift procedure in the treatment of the severely resorbed maxilla: a 5-year comparative longitudinal study. Int J Oral Maxillofac Surg. 2005 Dec;34(8):885-9.

5. Sorni M, Guarinós J, Garcia O, Peñarrocha M. Implant rehabilitation of the atrophic upper jaw: a review of the literature since 1999. Med Oral Patol Oral Cir Bucal. 2005 Apr 1;10(Suppl 1):E45-56.

6. Sorni M, Guarinós J, Peñarrocha M. Implants in anatomical buttresses of the upper jaw. Med Oral Patol Oral Cir Bucal. 2005 Mar-Apr;10(2):163-8.

7. Block MS, Haggerty CJ, Fisher GR. Nongrafting implant options for restoration of the edentulous maxilla. J Oral Maxillofac Surg. 2009 Apr;67(4):872-81.

8. Krekmanov L. Placement of posterior mandibular and maxillary implants in patients with severe bone deficiency: A clinical report of procedure. Int J Oral Maxillofac Implants. 2000 Sep-Oct;15(5):722-30.

9. Pi Urgell J, Revilla Gutiérrez V, Gay Escoda CG. Rehabilitation of atrophic maxilla: a review of 101 zygomatic implants Med Oral Patol Oral Cir Bucal. 2008 Jun 1;13(6):E363-70.

10. Maló P, Friberg B, Polizzi G, Gualini F, Vighagen T, Rangert B. Immediate and early function of Brånemark System implants placed in the esthetic zone: a 1-year prospective clinical multicenter study. Clin Implant Dent Relat Res. 2003;5(Suppl 1):37-46.

11. Rubo JH, Capello Souza EA. Finite-element analysis of stress on dental implant prosthesis. Clin Implant Dent Relat Res. 2010 Jun 1;12(2):105-13.

\section{Conclusion}

This study showed that the increase of implant angle not necessarily result in the increase of stress around the distal implant. High implant inclination to reduce the cantilever extension can decrease the stress values on the distal loads. Without the cantilever influence $15^{\circ}$ of inclination leds the stress to apical region while $35^{\circ}$ concentrated more stress in cervical region.

12. Maló P, Rangert B, Nobre M. All-on-4 immediate-function concept with Brånemark System implants for completely edentulous maxillae: a 1-year retrospective clinical study. Clin Implant Dent Relat Res. 2005;7(Suppl 1):S88-94.

13. Bonnet AS, Postaire M, Lipinski P. Biomechanical study of mandible bone supporting a four-implant retained bridge: finite element analysis of the influence of bone anisotropy and foodstuff position. Med Eng Phys. 2009 Sep;31(7):806-15.

14. Almeida EO, Rocha EP, Freitas-Júnior AC, Anchieta RB, Poveda R, Gupta N, et al. Tilted and short implants supporting fixed prosthesis in an atrophic maxilla: a 3D-FEA biomechanical evaluation. Clin Implant Dent Relat Res. 2013 Aug 5. [Epub ahead of print].

15. Silva-Neto JP, Pimentel MJ, Neves FD, Consani RL, Santos MB. Stress analysis of different configurations of 3 implants to support a fixed prosthesis in an edentulous jaw. Braz Oral Res. 2014 Jan-Feb;28(1):67-73.

16. Guichet DL, Caputo AA, Choi H, Sorensen JA. Passivity of fit and marginal opening in screw- or cemented-retained implant fixed partial denture designs. Int J Oral Maxillofac Implants. 2000 Mar-Apr;15(2):239-246.

17. Barbosa GAS, Bernardes SR, Mattos MGC, Fernandes-Neto AJ, Neves FD, Ribeiro RF. Estudo comparativo dos métodos de avaliação do ajuste vertical na interface pilar/implante. Cienc Odontol Bras. 2007 Jan-Mar;10(1):84-89.

18. Markarian RA, Ueda C, Sendyk CL, Laganá DC, Souza RM. Stress distribution after installation of fixed frameworks with marginal gaps over angled and parallel implants: a photoelastic analysis. J Prosthodont. 2007 Mar-Apr;16(2):117-22.

19. Goiato MC, Ribeiro PP, Pellizzer EP, Garcia Júnior IR, Pesqueira AA, Haddad MF. Photoelastic analysis of stress distribution in different retention systems for facial prosthesis. J Craniofac Surg. 2009 May;20(3):757-61.

20. Goiato MC, Tonella BP, Ribeiro PP, Ferraço R, Pellizer EP. Methods used for assessing stresses in buccomaxillary prostheses photoelasticity, finite element technique, and extensometry. J Craniofac Surg. 2009 Mar;20(2):561-4.

21. Tonella BP, Pellizzer EP, Falcón-Antenucci RM, Ferraço R, Almeida DAF. Photoelastic analysis of biomechanical behavior of single and multiple fixed partial prostheses with different prosthetic connections. J Craniofac Surg. 2011 Nov;22(6):2060-3. 
22. Abduo J, Bennani V, Waddell N, Lyons K, Swain M. Assessing the fit of implant fixed prostheses: a critical review. Int J Oral Maxillofac Implants. 2010 May-Jun;25(3):506-15.

23. White SN, Caputo AA, Anderkvist T. Effect of cantilever length on stress transfer by implant-supported prostheses. J Prosthet Dent. 1994 May;71(5):493-9.

24. Freitas-Júnior AC, Rocha EP, Assunção WG, Santos PH. Bioengenharia aplicada á odontologia: método dos elementos finitos versus fotoelasticidade. ImplantNews. 2007 Sep-Oct;4(5):469-76.
25. Begg T, Geerts GAVM, Gryzagoridis J. Stress patterns around distal angled implants in the all-on-four concept configuration. Int J Oral Maxillofac Implants. 2009 Jul-Aug;24(4):663-71.

26. Zampelis A, Rangert B, Heijl L. Tilting of splinted implants for improved prosthodontic support: a two-dimensional finite element analysis. J Prosthet Dent. 2007 Jun;97(6 Suppl):S35-43.

27. Bevilacqua M, Tealdo T, Menini M, Pera F, Mossolov A, Drago $\mathrm{C}$, et al. The influence of cantilever length and implant inclination on stress distribution in maxillary implant-supported fixed dentures. J Prosthet Dent. 2011 Jan;105(1):5-13. 